\title{
Utility of Eustachian valve for facilitating ASD device closures in defects with borderline mitral rims
}

\author{
Harikrishnan Kurup ${ }^{1}$, Arun Gopalakrishnan ${ }^{1}$, Deepa Sasikumar ${ }^{1}$, Venkatesh Gurajala ${ }^{1}$, \\ and Kavasseri Krishnamoorthy ${ }^{1}$ \\ ${ }^{1}$ Sree Chitra Tirunal Institute for Medical Sciences and Technology
}

June 20, 2021

\begin{abstract}
A prominent Eustachian valve in the right atrium has been reported to pose significant challenges during device closure of atrial septal defects. We describe the procedural aspects of device closure in an ASD with deficient rims and a redundant Eustachian valve. The prominent Eustachian valve provided extra stability in the anteroinferior aspect during device deployment and hence proved to be helpful for the procedure. It is important to consider this aspect while planning device closure
\end{abstract}

\section{Introduction}

Atrial septal defects (ASD) with more than 1.5:1 left to right shunts warrant closure by intervention or surgery. Interventional closure of ASDs is the preferred treatment modality if the rims of ASD are amenable to device closure. Deficiency of rims $(<5 \mathrm{~mm})$ is considered a contraindication for device closure of ASDs(1). The inferior vena cava rim and the atrioventricular valve rim are the most important borders to be assessed when considering a patient for device closure. ASD device closure has been attempted in patients with a borderline mitral rim if the other rims are adequate. Instability of the device and development of conduction disturbances and heart block have been attributed to attempted device closure in deficient atrioventricular valve rims because of the close proximity to the AV node. Eustachian valve frequently interferes with the proper deployment of device. Here, we describe a patient with borderline mitral rim where ASD device closure was successful because of the added stability provided by a prominent Eustachian valve.

\section{Case details}

A 7-year-old girl weighing $20 \mathrm{~kg}$, detected to have a heart murmur had a 21-mm ostium secundum ASD with more than 2:1 left to right shunt on transthoracic echocardiography. There was volume overload of the right atrium and ventricle without pulmonary hypertension. There was a prominent Eustachian valve (EV) of the Inferior vena cava (IVC). She underwent transesophageal echocardiography to characterize the ASD rims and suitability for device closure.

Tranesophageal echocardiography (TEE) demonstrated a $23 * 21 \mathrm{~mm}$ OS ASD with a mitral rim measuring $4.5 \mathrm{~mm}$ and IVC rim of $6 \mathrm{~mm}$. The mid-esophageal TEE 0-degree view (Figure 1A, Video 1) demonstrated a borderline mitral rim, with a prominent Eustachian valve very close to the mitral rim in contact with the interatrial septum (Figure $2 \mathrm{~A}$ ). The other rims appeared adequate for device closure (Figure $1 \mathrm{~B}, \mathrm{C}$ ). She underwent closure of the ASD using a $26 \mathrm{~mm}$ Lifetech HeartR ${ }^{\mathrm{TM}}$ atrial septal occluder device (Lifetech Scientific, Shenzhen, China). After deploying the LA disc, the device was pulled back across the septum and the waist deployed successfully in the first attempt. The Eustachian valve tissue adjacent to the AV rim prevented migration of the disc and stabilized the device despite a relatively small mitral rim. Figure 3 A-B shows the septal occluder in situ with the rims within the discs and a prominent EV. There was no residual flow, no conduction abnormalities and patient was discharged on Aspirin $5 \mathrm{mg} / \mathrm{kg} /$ day for 6 months. The 
patient is doing well at latest follow up with stable device position and without residual flow at $3^{\text {rd }}$ month follow up.

\section{Discussion}

Eustachian valve is a remnant of the embryonic sinus venosus valve. It is a fibromuscular triangular flap of tissue that extends from the lateral margin of the IVC orifice anteriorly and leftwards till the mouth of coronary sinus(2). It may be persisting as a large and redundant structure in the right atrium (more than $10 \mathrm{~mm}$ length) and may interfere with assessment and device closure of ASDs(3). It can be mistaken for the postero-inferior rim of the $\mathrm{ASD}(4)$. The device delivery cable may cause entrapment of the $\mathrm{EV}$ and inadvertent extraction of the EV(5). Furthermore, the prominent EV prevents apposition of the RA disc onto the septum and there may be residual atrial septal level shunt and predisposition to thrombus formation(6). There are reports of inadvertent surgical closure of a prominent Eustachian valve which was mistaken for an ASD where the patient presented with features of worsening cyanosis and IVC obstruction(7)(8). Butera et al reported on the pull push technique to avoid interferences of the EV with the delivery $\operatorname{system}(6)$.

Although all the prior reports describe the adverse effects of a redundant Eustachian valve, we describe a procedure where the EV actually helped to stabilize the device. We agree that caution needs to be exercised when planning for device closure of ASDs in patients with a prominent Eustachian valve. The index patient had borderline mitral rim measuring $4 \mathrm{~mm}$ which may have precluded device closure. However, the prominent EV near the mitral rim gave us confidence to attempt device closure. The prominent EV tissue prevented prolapse of the device during deployment because of the additional support offered in the antero inferior region (Figure 2B, Figure 3, Video 2). We antecedently chose the right upper pulmonary vein approach in this patient because of the borderline rims. The device closure was successful in the first attempt itself. There were no conduction disturbances. Development of AV conduction block during device closure of ASDs have been linked to the larger device size, proximity to AV node especially in deficient AV rims and injury during manipulation of the hardware(9)(10). The redundant EV in our case prevented slippage of the RA disc towards the atrioventricular junction and might have helped in avoiding injury to the AV node. We confirmed stability of the device by TEE in standard views and also confirmed uninterrupted IVC flow post deployment. There was no interference during cable manipulation as we had confirmed that the sheath was coursing freely across to the left atrium and the cable along with device was fully within the sheath prior to deployment.

We demonstrate successful ASD device closure facilitated by the redundant Eustachian valve in a patient with deficient mitral rims. Heightened caution is required following the recognition of this anomaly. However, it may prove beneficial in certain circumstances as elaborated.

Author contributions: Concept/ data collection/ drafting article- HKN; HKN, AGK, DSK, VG, KMK critically reviewed the manuscript. All authors approved the final version.

\section{References}

1. Silvestry FE, Cohen MS, Armsby LB, Burkule NJ, Fleishman CE, Hijazi ZM, et al. Guidelines for the Echocardiographic Assessment of Atrial Septal Defect and Patent Foramen Ovale: From the American Society of Echocardiography and Society for Cardiac Angiography and Interventions. J Am Soc Echocardiogr Off Publ Am Soc Echocardiogr. 2015 Aug;28(8):910-58.

2. Shereen R, Lee S, Salandy S, Roberts W, Loukas M. A comprehensive review of the anatomical variations in the right atrium and their clinical significance. Transl Res Anat. 2019 Nov 1;17:100046.

3. Moral S, Ballesteros E, Huguet M, Panaro A, Palet J, Evangelista A. Differential Diagnosis and Clinical Implications of Remnants of the Right Valve of the Sinus Venosus. J Am Soc Echocardiogr. 2016 Mar 1;29(3):183-94.

4. Krishnamoorthy K, Gopalakrishnan A, Deepa S, Sivasubramonian S. Eustachian valve - Masquerading ASD rim. Indian Heart J. 2017 Apr 1;69. 
5. Onorato E, Pera IG, Melzi G, Rigatelli G. Persistent redundant Eustachian valve interfering with Amplatzer PFO occluder placement: anatomico-clinical and technical implications. Catheter Cardiovasc Interv Off J Soc Card Angiogr Interv. 2002 Apr;55(4):521-4.

6. Butera G, Montinaro A, Carminati M. The "pull-push" technique to deal with a redundant eustachian valve interfering with placement of a PFO occluder. Catheter Cardiovasc Interv Off J Soc Card Angiogr Interv. 2006 Dec;68(6):961-4.

7. Becker A, Buss M, Sebening W, Meisner H, Döhlemann C. Acute inferior cardiac inflow obstruction resulting from inadvertent surgical closure of a prominent Eustachian valve mistaken for an atrial septal defect. Pediatr Cardiol. 1999 Apr;20(2):155-7.

8. Akpinar I, Guray Y, Demirkan B, Boyaci AA, Basar N, Cagli K, et al. Rare postsurgical complication of atrial septal defect closure: right inflow obstruction due to inadvertent suturing of eustachian valve to interatrial septum. Can J Cardiol. 2011 Dec;27(6):868.e9-10.

9. Wang Y, Hua Y, Li L, Wang X, Qiao L, Shi X, et al. Risk factors and prognosis of atrioventricular block after atrial septum defect closure using the Amplatzer device. Pediatr Cardiol. 2014 Mar;35(3):550-5.

10. Suda K, Raboisson M-J, Piette E, Dahdah NS, Miró J. Reversible atrioventricular block associated with closure of atrial septal defects using the amplatzer device. J Am Coll Cardiol. 2004 May 5;43(9):1677-82.

\section{Figure and video legends}

Figure 1A, Video 1 shows mid-esophageal TEE 0-degree view demonstrating a borderline mitral rim, with a prominent Eustachian valve very close to the mitral rim in contact with the interatrial septum. The arrow shows the prominent Eustachian valve. Figure $1 \mathrm{~B}, \mathrm{C}$ shows the other rims of the ASD in mid-esophageal TEE 45 degrees and 90 degrees views which appeared adequate for device closure.

Figure 2 A : Illustration demonstrating right atrium, left atrium, atrial septal defect and the prominent Eustachian valve, with a small mitral rim.

Figure 2 B : Illustration to show the device position in relation to the mitral rim and the arrow shows the line of pressure exerted by the device. The Eustachian valve adjacent to mitral rim provides added support in this area.

Figure 3 A-B, Video 2 shows the septal occluder in situ with the rims within the discs and a prominent EV in mid esophageal TEE 0 degree and 45 degrees respectively.

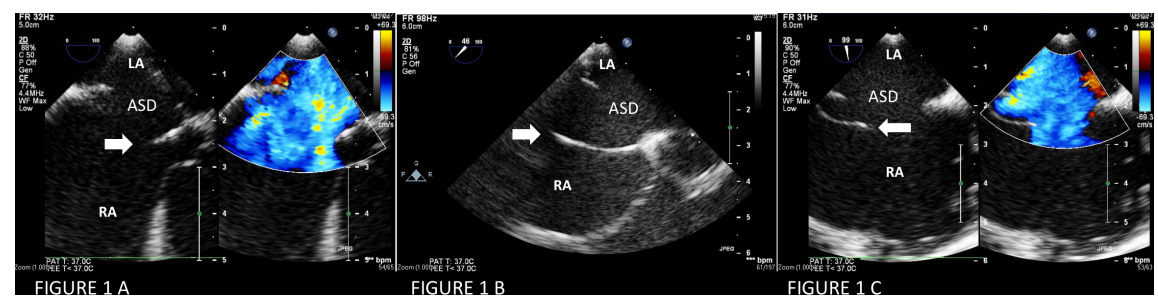



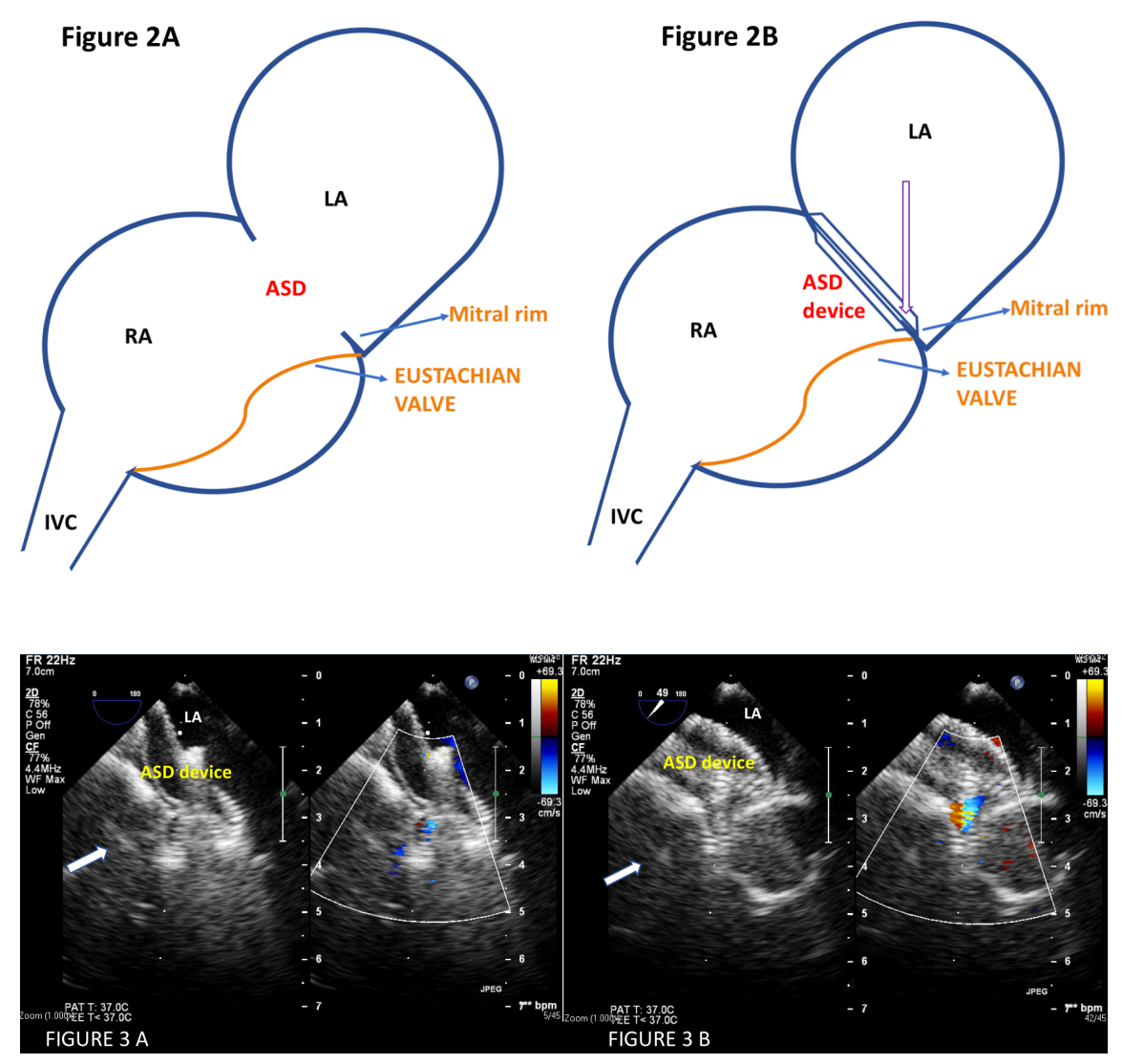